\title{
Nuclear expression of Gli-1 is predictive of pathologic complete response to chemoradiation in trimodality treated oesophageal cancer patients
}

Roopma Wadhwa ${ }^{1}$, Xuemei Wang ${ }^{2}$, Veerabhadran Baladandayuthapani ${ }^{2}$, Bin Liu ${ }^{3}$, Hironori Shiozaki ${ }^{1}$, Yusuke Shimodaira ${ }^{1}$, Quan Lin ${ }^{1}$, Elena Elimova ${ }^{1}$, Wayne L Hofstetter ${ }^{4}$, Stephen G Swisher ${ }^{4}$, David C Rice ${ }^{4}$, Dipen M Maru ${ }^{5}$, Neda Kalhor ${ }^{5}$, Manoop S Bhutani ${ }^{6}$, Brian Weston ${ }^{6}$, Jeffrey H Lee ${ }^{6}$, Heath D Skinner ${ }^{7}$, Ailing W Scott ${ }^{1}$, Dilsa Mizrak Kaya ${ }^{1}$, Kazuto Harada ${ }^{1}$, Donald Berry ${ }^{2}$, Shumei Song ${ }^{1}$ and Jaffer A Ajani ${ }^{*}, 1$

${ }^{1}$ Department of Gastrointestinal Medical Oncology, University of Texas M. D. Anderson Cancer Center, 1515 Holcombe Blvd, Houston, TX 77030, USA; ${ }^{2}$ Department of Biostatistics, University of Texas M. D. Anderson Cancer Center, 1515 Holcombe Blvd, Houston, TX 77030, USA; ${ }^{3}$ Department of Genetics, University of Texas M. D. Anderson Cancer Center, 1515 Holcombe Blvd, Houston, TX 77030, USA; ${ }^{4}$ Department of Thoracic Oncology, University of Texas M. D. Anderson Cancer Center, 1515 Holcombe Blvd, Houston, TX 77030, USA; ${ }^{5}$ Department of Pathology, University of Texas M. D. Anderson Cancer Center, 1515 Holcombe Blvd, Houston, TX 77030, USA; ${ }^{6}$ Department of Gastroenterology, Hepatology, and Nutrition, University of Texas M. D. Anderson Cancer Center, 1515 Holcombe Blvd, Houston, TX 77030, USA and '7Department of Radiation Oncology, University of Texas M. D. Anderson Cancer Center, 1515 Holcombe Blvd, Houston, TX 77030, USA

Background: Predictive biomarkers or signature(s) for oesophageal cancer (OC) patients undergoing preoperative therapy could help administration of effective therapy, avoidance of ineffective ones, and establishment new strategies. Since the hedgehog pathway is often upregulated in OC, we examined its transcriptional factor, Gli-1, which confers therapy resistance, we wanted to assess Gli-1 as a predictive biomarker for chemoradiation response and validate it.

Methods: Untreated OC tissues from patients who underwent chemoradiation and surgery were assessed for nuclear Gli-1 by immunohistochemistry and labelling indices (LIs) were correlated with pathologic complete response (pathCR) or < pathCR (resistance) and validated in a unique cohort.

Results: Initial 60 patients formed the discovery set (TDS) and then unique 167 patients formed the validation set (TVS). 16 (27\%) patients in TDS and 40 (24\%) patients in TVS achieved a pathCR. Nuclear Gli-1 LIs were highly associated with pathCR based on the fitted logistic regression models $(P<0.0001)$ in TDS and TVS. The areas under the curve (AUCs) for receiver-operating characteristics (ROCs) based on a fitted model were 0.813 (fivefold cross validation (0.813) and bootstrap resampling (0.816) for TDS and 0.902 (fivefold cross validation (0.901) and bootstrap resampling (0.902)) for TVS. Our preclinical (including genetic knockdown) studies with FU or radiation resistant cell lines demonstrated that Gli-1 indeed mediates therapy resistance in OC.

Conclusions: Our validated data in OC show that nuclear Gli-1 LIs are predictive of pathCR after chemoradiation with desirable sensitivity and specificity.

*Correspondence: Professor JA Ajani; E-mail: jajani@mdanderson.org

Received 3 June 2017; revised 15 June 2017; accepted 21 June 2017; published online 20 July 2017

(C) 2017 Cancer Research UK. All rights reserved 0007-0920/17 
The incidence of oesophageal cancer (OC), particularly adenocarcinoma (EAC), has risen in recent decades. In 2015, the estimated number of new cases and deaths due to OC in the United States (US) are 16980 and 15 590, respectively (American Cancer Society (2015)). In the US, standard approach for localised OC (LOC) is chemoradiation followed by surgery (when feasible) (van Hagen et al, 2012; Ajani et al, 2015a). Approximately $25 \%$ of patients' OCs are highly sensitive to chemoradiation and result in a pathologic complete response (pathCR, defined as no cancer cells in the resected specimen). PathCR patients, generally, have a better outcome than those patients whose OCs achieve < pathCR (Berger et al, 2005; Chirieac et al, 2005; Rohatgi et al, 2005a, b; Rizk et al, 2007; Donahue et al, 2009; Cheedella et al, 2013). However, for a given patient, the degree of response and the prognosis are frustratingly unpredictable. Validated reliable clinical variables (Ajani et al, 2012) or biomarker(s) are currently unavailable. We have previously reported that ALDH1 in OC tissues appears to be related to resistance to chemoradiation (Ajani et al, 2014), however, further research with additional biomarkers is necessary prior to clinical implementation and the biomarker(s) or signature(s) must accommodate inherent heterogeneity of OC.

One potential advantage of this research trajectory, although this concept remains theoretical, is to identify a patient whose OCs may have extreme results in the response spectrum. For example, identification of patients whose OC are destined to achieve a pathCR could be the subjects of an oesophageal preservation strategy and those with extremely resistant OC could move directly to surgery (bypassing chemoradiation) until we have tools to overcome resistance. We have previously reported that the hedgehog $(\mathrm{HH})$ pathway is dysregulated in OC, it mediates resistance to therapy, and inhibition of the $\mathrm{HH}$ pathway overcomes resistance to cytotoxics and radiation (Sims-Mourtada et al, 2006, 2007). We also demonstrated that Gli-1 can participate in a crosstalk with mTOR pathway to induce secondary resistance to $\mathrm{HH}$ inhibition in OC (Wang et al, 2012). The HH pathway and associated overexpression of Gli-1 has been reported by others as oncogenic (Onishi and Katano, 2011), including in basal cell carcinomas (Rudin et al, 2009; Von Hoff et al, 2009), small cell lung cancer (Park et al, 2011), medulloblastomas (Pasca di Magliano and Hebrok, 2003), breast cancer (Souzaki et al, 2011), prostate cancer (Karhadkar et al, 2004), and pancreas cancer (Nagai et al, 2008; He et al, 2011). In squamous cell OC, the Gli-1 nuclear expression was reported as an independent variable for relapse and poor prognosis (Yoshikawa et al, 2008). Gli-1 signalling is intertwined with cancer stem cell (CSC) maintenance (Po et al, 2010; Coni et al, 2013; Ajani et al, 2015b). Gli-1 has been amply implicated in resistance to therapy through the mechanism of inducible glucuronidation (Zahreddine et al, 2014). In glioma patients, a positive correlation was observed between Gli-1 expression and tumour recurrence (Cui et al, 2010). Based on our research and the contributions by others, we hypothesised that the expression of nuclear Gli-1 could be predictive of response, particularly pathCR, to chemoradiation in OC patients. We are more interested in discovering a predictive biomarker or signature because it is more likely to help change clinical practice rather than a prognostic biomarker (where the chance of its being a therapeutic target could be low). Gli-1 as a predictive biomarker for OC (or in any other tumour type) has not been reported, to our knowledge.

\section{MATERIALS AND METHODS}

Patient population and therapy. Through an institutional review board (IRB) approved protocol and projects supported by the National Cancer Institute and UT M. D. Anderson Cancer Center (MDACC), pre-treatment cancer specimens were obtained from
227 patients who met the following criteria: had localised (T1N1, T2, T3 with any $\mathrm{N}$ or with M1a), histologically confirmed adenocarcinoma or squamous cell carcinoma of the thoracic esophagus, and were treated chemoradiation followed by surgery. All patient material was collected after obtaining an informed written consent. Following institutional standards, each patient underwent complete baseline clinical staging and was discussed in the weekly Oesophageal Cancer Conference prior to the initiation of therapy. Positron emission tomography was allowed when feasible. Chemotherapy included a fluoropyrimidine with either a platinum compound or taxane with concurrent 50.4 Gray radiation in 28 fractions. Surgery was performed $\sim 6-7$ weeks after the completion of chemoradiation. The surgical specimens were scored by the method described by (Chirieac et al, 2005). This method has been independently validated in a multi-institutional setting ( $\mathrm{Wu}$ et al, 2007). Specimens were scored by two team members (independently) in a blinded manner to prevent the potential bias. Each specimen was designated as pathCR or <pathCR (extreme resistance defined as $>50 \%$ residual OC was also assessed).

All patients were followed for 5 years or until death as described previously (Ajani et al, 2014).

Statistical methods. Patient characteristics were summarised using median (range) for continuous variables and frequency (percentage) for categorical variables. Overall survival (OS) was defined as the time interval between surgery and the date of death due to any cause. Patients who were alive were censored at the last follow-up date. Progression-free survival (PFS) was defined as the time interval between surgery and the date of relapse or death due to any cause. Patients who were alive and relapse-free were censored at the last follow-up date. The probabilities of OS and PFS were estimated using the method of Kaplan and Meier (Kaplan and Meier, 1958). Log-rank test (Mantel, 1996) was used to assess the difference in OS or PFS between subgroups of patients. Univariate logistic regression model was fit to assess the association between Gli-1 and the probability of achieving pathCR. Based on fitted model, a plot of Gli-1 LI (\%) vs the predicted probability of pathCR was created. The receiver operating characteristics (ROC) curve was also generated to derive the area under the curve (AUC) and to assess the overall predictive ability of the fitted model. Two resampling techniques (cross validation and bootstrapping) were used to validate the estimated AUC. The sensitivity, specificity, positive predictive value, negative predictive value and predictive accuracy for pathCR based on various cutoff values of Gli-1 are also summarised. All statistical analyses were performed with SAS and Splus software.

\section{Preclinical methods}

Cell lines and reagents. The human EAC cell lines SKGT4 (SK4) and Flo-1 were acquired from our institution and described previously (Soldes et al, 1999; Raju et al, 2006). To establish 5-FUresistant subclones, SKGT4-RF (SK4-RF), SK-4 parenteral cells were treated at their IC50 concentration of 5-FU for 3-5 weeks, and then the concentration of 5-FU was increased every two to three weeks until the resistant clones were established. This procedure was repeated four times. The establishment of these 5-FU-resistant subclones took 3-6 months and newly derived 5FU-resistant clones were designated SK4-RF. Similarly; Flo-1 cells were made resistant to radiation and termed Flo-1 XTR. To establish radiation resistant subclones, Flo-1 parental clones were irradiated to $2 \mathrm{~Gy}$ and maintained in culture. The surviving clones were allowed to achieve $80 \%$ confluency ( $\sim 1-2$ weeks) and again irradiated to $2 \mathrm{~Gy}$. This process was performed a total of four times. Once complete, cells were stored at $-80^{\circ} \mathrm{C}$ until use. Cells were kept in continuous culture for less than 2-3 weeks, with subsequent experiments using fresh lots of cells. These cells were authenticated and re-characterised in the core facility of MDACC 
every 6 months. Cells were cultured in DMEM supplemented with $10 \%$ fetal bovine serum and antibiotics $(100 \mathrm{mg} / \mathrm{ml}$ streptomycin and $100 \mathrm{IU} / \mathrm{ml}$ of penicillin; Ajani et al, 2014) and incubated at $37^{\circ} \mathrm{C}$ in $5 \%$ CO2. 5-FU was purchased from Sigma Chemical Co. (St Louis, MO, USA).

Gli-1 inhibitor was purchase from Selleck Chemical LLC (Houston, TX, USA) and reconstituted in $100 \%$ ethanol. The Lenticrispr Gli1 was constructed in our lab using the CRISPRs (clustered regularly interspaced short palindromic repeats)/Cas9 system. Guide RNAs design follows MIT Feng Zhang's website http://crispr.mit.edu/ or German Cancer Research Center's E-Crisp website http://www.ecrisp.org/E-CRISP/designcrispr.html. Human Glil gene is designed with 2 targets of guide RNA sequences as below.

hGli1.E5.gRNA3.F 5' - caccgGGGAAGGGTCCCCGGGACTG-3' hGli1.E5.gRNA3.R 5' -aaacCAGTCCCGGGGACCCTTCCCc-3' hGli1.E5.gRNA4.F 5' -caccgAGGAAGGCGAGGGCCCTTTT-3' hGli1.E5.gRNA4.R $5^{\prime}$-aaacAAAAGGGCCCTCGCCTTCCTc-3'

With $100 \mu \mathrm{M} 50 \mu \mathrm{l}$ of each primer added together, each pair of guide RNA sequences is formed into duplexes in a heating block heated to $100 \mathrm{C}$ and cooled gradually by itself. The duplexes are then used as inserts ligated using T4 DNA ligase(NEB, Ipswich, MA, USA) into LGP (lentiGuidePuro, Addgene) cut by BsmbI (NEB). The ligates are transformed into Stabl3 competent cells, resultant clones are screened by the sises of inserts and verified by sequencing.

LGP plasmids with right inserts of GlilgRNAs are then cotransfected with pLenti-Cas9-Blast, pCMV.Dr8.2 and pCMVVSV.G with ratio of $10: 10: 10: 1$ into HEK293T cells with $\sim 70 \%$ confluency by Lipofectamine2000 (Carlsbad, CA, USA) in six-well plates. Supernatants are collected $48 \mathrm{~h}$ later and recollected $24 \mathrm{~h}$ later for second time. Lentiviral supernatants are centrifuged and clear upper solutions are used for immediate transduction or kept in $-80^{\circ} \mathrm{C}$ freezer for later use.

Target cell line Flo1-XTR is seeded in six-well plates with $\sim 70 \%$ confluency, lentiviral supernatants are added with $8 \mathrm{~mm}$ polybrene, transduced cells are then selected by puromycin at concentration determined by kill curves for 4-6 days. Surviving cells are then expanded and positive pools are screened by western blot of appropriate antibodies.

Tissue specimens and handling. Untreated OC biopsies were used as described previously (Ajani et al, 2014). OC histology and $\geqslant 50 \%$ tumour cellularity were confirmed before staining for Gli-1. The tissue sections were $4 \mu$ thick. Immunohistochemistry staining for Gli-1 were performed using anti-Gli-1 ab92611 (1:400) antibody. Positive and negative controls were used previously reported (Sims-Mourtada et al, 2006). Two team members independently reviewed the slides to establish Gli-1 LIs, on the basis of percentage of tumour cell nuclei stained and the staining intensity. Joint consensus was made for discordant cases using a double-headed microscope for re-review.

Cell proliferation assay. Cell proliferation on SK4 and Flo-1 OC cells and their resistant counterpart SK4-RF and Flo-1 XTR were performed using the CellTiter 96 aqueous nonradioactive cell proliferation assay (MTS) according to the instructions of the manufacturer (Promega Co., Madison, WI, USA) as described as before (Song et al, 2015).

Clonogenicity assay. Single cells (800/well) were seeded in triplicates onto a six-well plate (Falcone). The cell culture medium and incubation condition have been described in the Cell lines and reagents. Twenty-four hours later, cells were either treated with GANT61 $(10 \mu \mathrm{M})$ or same amount $100 \%$ ethanol as negative control. Nine days after seeding, the cells were washed and then fixed with $3.7 \%$ paraformaldehyde for $20 \mathrm{~min}$. Subsequently, the cells were washed twice in tap water and stained with $0.3 \%$ crystal violet for $2 \mathrm{~min}$ at room temperature. Following washing with tap water, colonies were counted by eye.

Tumour sphere formation assay. Single cells (800/well) were seeded in triplicate onto a 24-well ultra-low attachment plate (Corning) in serum free DMEM/F-12 supplemented with $10 \mathrm{ng}$ epidermal growth factor, $5 \mu \mathrm{g} / \mathrm{ml}$ insulin, $0.5 \mu \mathrm{g} / \mathrm{ml}$ hydrocortisone, and bovine pituitary extract (Invitrogen). After 12 days of culture under the same condition as described in the Cell lines and reagents, tumour spheres formed and their number was counted under a microscope.

Matrigel invasion assay. The invasive capacity of cells was studied by using invasion chambers with 0.8 um pore sise (Greiner bio-one) inserted into a 24-well plate (Falcone). A signal cell suspension containing $2.5 \times 10^{4}$ was added into the invasion chamber. After $24 \mathrm{~h}$ of incubation in the same environment described in the Cell lines and reagents, cells on the upper surface of the invasion chamber were removed with cotton swabs. Invaded cells which adhered on the lower surface of the membrane were fixed and stained with Diff-Quik (Siemens), then photographed under a microscope and counted.

Protein extraction and western blot analysis. Protein isolation and Western blot analyses were performed in Sk4/Sk4-RF and Flo1/Flo-1 XTR OC cells as previously described (Song et al, 2014) and immunoreactive bands were visualised by chemiluminescence detection.

Reverse-phase protein arrays. The reverse-phase protein arrays (RPPA) analysis was performed in Sk4 cells and its resistant clone Sk4-FR cell lysate in the RPPA core facility of MDACC. Samples were serially diluted 2 -fold for 5 dilutions and probed with 175 antibodies and arrayed on nitrocellulose-coated slides. The relative protein levels were normalised for protein loading and determined by interpolation of each dilution curve from the standard curve as previously described (Hennessy et al, 2010). Gene set enriched analysis (GSEA) conducted by a bioinformatician (Dr Bin Liu).

Real-time quantitative reverse transcription PCR. Total RNAs from cell cultures are extracted by using Trizol (Ambion, Austin, TX, USA) concentrations of RNAs are measured by Nanodrop 1000 (Nanodrop, Wilmington, DE). First strand cDNAs are synthesised by Reverse transcription PCR using Invitrogen's Superscript III kit (Invitrogen, Carlsbad, CA, USA). Quantitative RT PCR measuring mRNA expression levels are performed by ABI 7500 (Life Technologies, Grand Island, NY, USA) using the following listed primers. The fluorescence threshold cycle (Ct) value was determined for each gene and normalised with GAPDH. Relative quantitation is calculated by using $\mathrm{RE}=2^{(-\Delta \Delta \mathrm{Ct})}$. The primers used as followings: Reference primers: hGAPDH $5^{\prime}$ ACCCAGAAGACTGTGGATGG-3', hGAPDH-3 5' ${ }^{\prime}$-TCTAGACGGCAGGTCAGGTC-3';

Target genes' primers are:

hGli1.mRNA.F 5'-CCAGCGCCCAGACAGAG-3'

hGli1.mRNA.R 5'-ACAGTCCTTCTGTCCCCACA-3' hGli2.mRNA.F 5'-CTCTCCTTTGGTGGTGGCT-3'

hGli2.mRNA.R 5'-GGTGTGTGTCCAAAGGCTG-3'; hSHH.mRNA.F 5'-CCAATTACAACCCCGACATC-3' hSHH.mRNA.R 5'-AGTTTCACTCCTGGCCACTG-3'

\section{RESULTS}

Patients, chemoradiation response, and survival. Initial 60 patients formed the discovery set (TDS) and subsequent 167 patients formed the validation set (TVS). The group prior to proceeding with TVS reviewed results on TDS set. Patient 
characteristics of TDS and TVS are summarised in Table 1. For TDS, the median follow up time was 44.4 months and median OS was 54.6 months (95\% CI: 34.1 to not estimable). In TDS, 31 patients have died and the median PFS was 30.3 months (95\% CI: 17 to not estimable). In TVS, the median follow up time of all patients was 81.5 months and the median OS was 41.8 months (95\% CI: 28.2 -53.3 months). The PFS was 21.6 months (95\% CI: 14.4-38.4 months). Sixteen (27\%) patients in TDS and $40(24 \%)$ patients in TVS had a pathCR and the rest had < pathCR. The median OS of pathCR patients was longer than that of those who's OCs achieved a < pathCR (TDS, median OS not reached in pCR patients $v s$ median OS of 34.1 months in $<$ pCR patients, $P=0.005$; TVS, median OS of 60 months in pCR patients $v s$ 36.9 months in $<$ pCR patients, $P=0.10$ ).

Gli-1 expression and correlation with response. The median nuclear Gli-1 LI was 20\% (range, 0-95\%). On the basis of the fitted the logistic regression model, Gli-1 was significantly associated with the probability of achieving a pathCR in TDS (Table 2) and in TVS (Table 3). Patients with a higher Gli-1 LIs had a lower probability of pathCR (TDS, OR [odds ratio] $=0.46$; 95\% CI $0.33-$ $0.64 ; P=<0.0001$. TVS, OR $=0.84 ; 95 \%$ CI: $0.78-0.90 ; P$ value $<0.0001)$. Figure $1 \mathrm{~A}$ and $\mathrm{B}$ show that most pathCR patients gravitated towards lower nuclear Gli-1 LIs and the resistant population towards higher LIs.

On the basis of the fitted logistic regression model, the AUC of the ROC (Figure 2A and B) for Gli-1 was 0.813 (fivefold cross validation (0.813) and bootstrap resampling (0.816) for TDS and 0.902 (fivefold cross validation (0.901) and bootstrap resampling (0.902)) for TVS. Supplementary Tables 1 and 2 show the estimated sensitivity, specificity, positive predictive value (PPV) and negative predictive value (NPV) and the overall predictive accuracy of pathCR based on choosing different cutoff values for Gli-1. The results demonstrate a relatively high specificity $(>85 \%)$ for lower nuclear Gli-1 LIs ( $\leqslant 10 \%)$.

Chemo/radiation-activated Gli-1 and Shh expression. Gli-1 and Shh are important hedgehog pathway $(\mathrm{Hh})$ signalling components and are associated with therapy response/resistance. We observed that Gli-1 and its ligand Shh have increased expression in EAC tumour tissues compared to Barrett's premalignant tissues (Supplementary Figure S1) and we found nuclear expression of Gli-1 was significantly associated therapy response. Thus, the mechanism underlying the effect of chemo/radiation on the $\mathrm{Hh}$ signalling was investigated. It was observed that 5-FU or radiation induced resistant cells SK4-RF and Flo-1 XTR had higher

\begin{tabular}{|l|l|c|c|}
\hline \multicolumn{2}{|l|}{ Table 1. Patient characteristics } \\
\hline Covariate & \multicolumn{1}{|c|}{ Levels } & $\begin{array}{c}\text { Discovery set } \\
\text { N (\%) }\end{array}$ & $\begin{array}{c}\text { Validation set } \\
\text { N (\%) }\end{array}$ \\
\hline Age (years) & Median & 59 & 62 \\
\hline & Range & $35-76$ & $27-80$ \\
\hline Gender & Male & $59(98.33)$ & $149(89.22)$ \\
\hline & Female & $1(1.67)$ & $18(10.78)$ \\
\hline Ethnicity & White & $58(96.67)$ & $152(91.02)$ \\
\hline & Hispanic & $1(1.67)$ & $13(7.78)$ \\
\hline & African American & $1(1.67)$ & $2(1.2)$ \\
\hline & IIA & $24(40.00)$ & $59(35.33)$ \\
\hline & IIB & $3(5.00)$ & $7(4.19)$ \\
\hline & III & $30(50.00)$ & $81(48.5)$ \\
\hline & IVA & $2(3.33)$ & $9(5.39)$ \\
\hline & IVB & $1(1.67)$ & $4(2.40)$ \\
\hline & X & $0(0.00)$ & $7(4.19)$ \\
\hline${ }^{2}$ AJCC 6th edition. & \multicolumn{3}{|l}{} \\
\hline
\end{tabular}

expression of nuclear Gli-1 and Shh (Figure 3A). Increased mRNA levels of Gli-1, Gli-2 and Shh in chemoresistant cells, SK4-RF were confirmed using quantitative real-time PCR (Figure 3B). RPPA further demonstrated that many oncogenes were enriched in therapy resistant cells (SK4-RF) compared to the parental cells (Figure 3C). These data indicate that chemo/radiation therapy activates the $\mathrm{Hh}$ signalling which may mediate the therapy response/resistance.

Table 2. Logistic regression model for pathCR in TDS $(n=60$; path $C R=16$ )

\begin{tabular}{l|c|c|c|}
\hline Variable & OR & $95 \%$ Cl & $P$-value \\
\hline Intercept & - & - & $<0.0001$ \\
\hline Gli-1*100 & 0.46 & $0.33-0.64$ & $<0.0001$ \\
\hline $\begin{array}{l}\text { Abbreviations: OR=odds ratio; pathCR = pathologic complete response; TDS =the } \\
\text { discovery set. }\end{array}$
\end{tabular}

Table 3. Logistic regression model for pathCR in TVS $(n=167$; pathCR $=40$ )

\begin{tabular}{l|c|c|c|}
\hline Variable & OR & $\mathbf{9 5 \% ~ C l}$ & $\boldsymbol{P}$-value \\
\hline Intercept & - & - & 0.003 \\
\hline Gli-1*100 & 0.84 & $0.78-0.90$ & $<0.0001$ \\
\hline $\begin{array}{l}\text { Abbreviations: OR=odds ration; pathCR=pathologic complete response; TVS = the } \\
\text { validation set. }\end{array}$
\end{tabular}

\section{A}
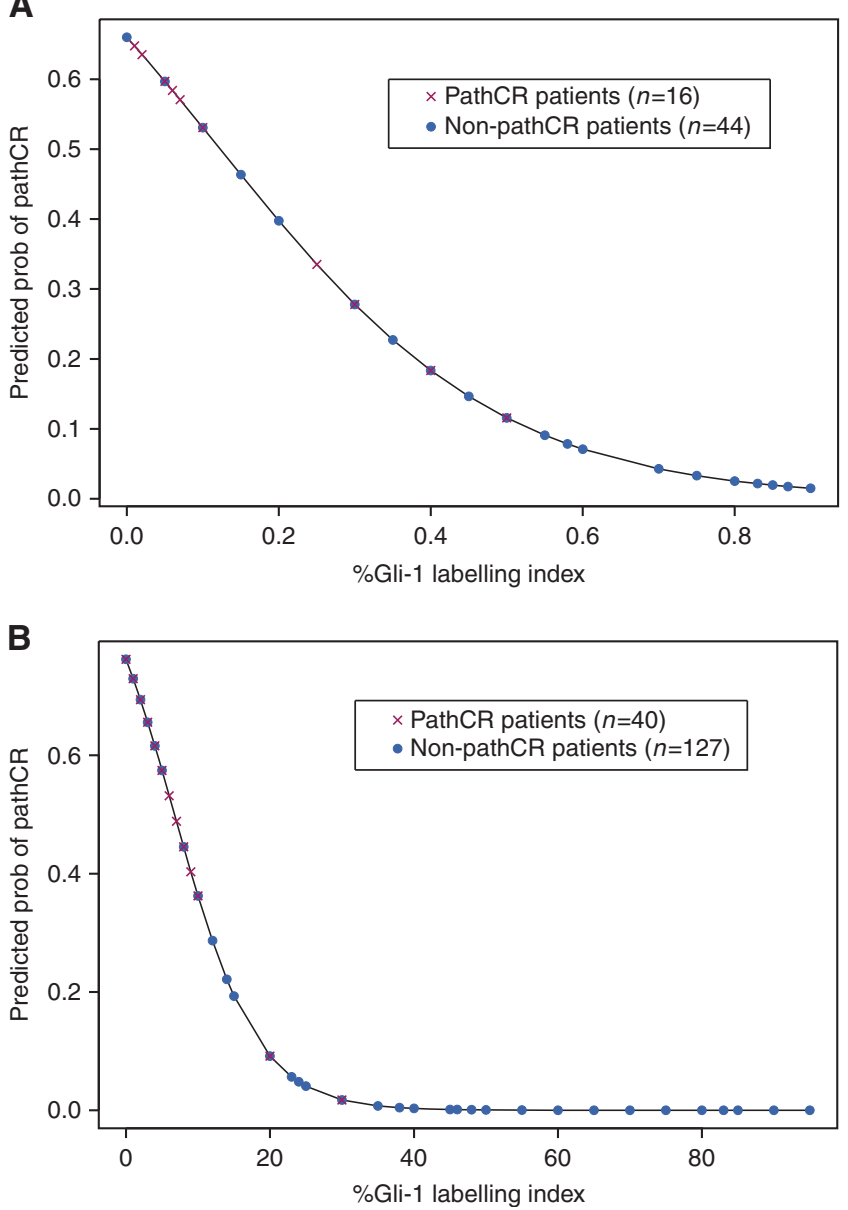

Figure 1. (A) Plot of $\%$ Gli-1 LI vs the predicted probability of pathCR based on the fitted model in Table 2 for TDS (the discovery set). (B) Plot of \% Gli-1 LI vs the predicted probability of pathCR based on the fitted model in Table 3 for TVS (the validation set). 

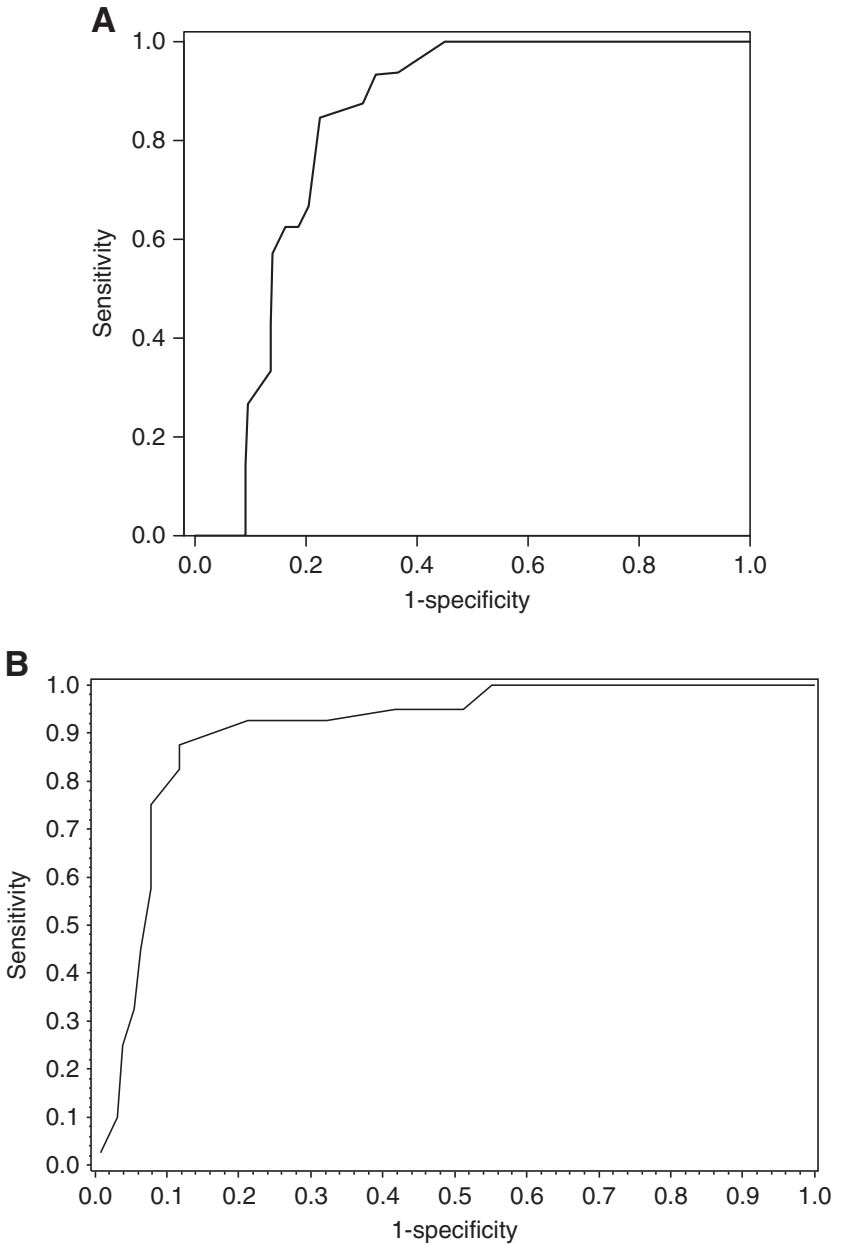

Figure 2. (A) ROC AUC indicating sensitivity and specificity based on the fitted model in Supplementary Table S1 for TDS (the discovery set; $n=60$ ). (B) ROC AUC indicating sensitivity and specificity based on the fitted model in Supplementary Table S2 for TVS (the validation set; $n=167$ ).

Chemo/irradiation endows EAC cells with high potentials of cell proliferation, clonogenecity, and tumour sphere formation in vitro in OC cells. After showing that chemo/radiation resistant cells over-expressed Gli-1 and Shh, we sought to determine if the resistant cells conferred more malignant behaviour. As expected, we found that both chemo (SK4-RF) and radiation resistant cells (Flo-1 XTR) had higher rates of proliferation compared to their parental counterparts (Figure 3D). Clonogenicity has also been employed as a metric of resistance to radiation and chemotherapy. Our colonygenicity assay further confirmed that radiation resistant Flo-1 XTR cells dramatically increased colony formation (Figure 3E). The formation of tumour spheres has been considered as a surrogate indicator of CSC properties in epithelial cancers (Dontu et al, 2003). We analysed the tumour sphere formation in Flo-1 XTR as well as in parental cell line Flo-1. The irradiation survived cells Flo-1 XTR proliferated and generated larger tumour spheres, while parental Flo- 1 cells did not form any tumour spheres (Figure 3F, left panel). The number of tumour spheres developed in the radiation resistant cells (Flo-1 XTR) was significantly higher and larger than that of parental cell line Flo-1 (Figure 3F, right panel). This indicates that irradiation treatment endows CSC properties to OC cells.

Higher proliferation and tumour sphere formation rates are correlated with higher expression of Gli-1. The chemo (SK4-RF) and radiation (Flo-1 XTR) resistant cell lines showed higher proliferation and tumour sphere formation rates than the parental cell lines. To investigate the cause-effect relationship, we used
lentCrisp/cas9 system (Supplementary Figure S2A and B) and GANT61 (Supplementary Figure S2C and D), a specific Gli-1 inhibitor to genetically knockdown Gli-1 expression or pharmacologically block the Gli-1 signalling pathway respectively. We found that both (genetic knockdown of Gli-1 and pharmacologic inhibition of Gli-1 protein) significantly decreased cell proliferation and sensitised cells to radiation (Supplementary Figure S2B and D). Also, tumour sphere formation (Supplementary Figure S2A) was dramatically reduced by lentCrisp/cas9 system, while cell invasion (Supplementary Figure S2C) was decreased as well.

\section{DISCUSSION}

The research portfolio for patients with localised OC has generally been limited to empiric clinical trials to improve the outcome of patients. In this regard, some advances have been realised (Cooper et al, 1999; Wu et al, 2007; van Hagen et al, 2012; Ajani et al, 2015a). However, chemoradiation and surgery are associated with considerable morbidity and surgery particularly results in life-altering consequences. The current approach that emphasises baseline clinical staging and stage grouping in order to make initial and long-term therapy decisions do not account for inherent molecular heterogeneity of OC. Thus some patients seem to benefit and others do not but at the outset one has no idea what therapy is optimum for a given patient. In addition to not being able to select an effective therapy for a given patient, we also have little knowledge of molecular biology of OC. Recent effort by The Cancer Genome Atlas (TCGA) has demonstrated stark biology difference between squamous cell carcinoma and adenocarcinoma, however, several subgroups (with different genomic makeups) have also been described. (Cancer Genome Atlas Research N et al, 2017) TCGA analysis provides impetus for further exploration before such platforms can provide clinical guidance. Therefore, our general knowledge needs to considerably expand. A glaring example is that EGFR is overexpressed in squamous and adenocarcinoma of the esophagus and is prognostic (Wang et al, 2007); however, the assumption that these tumours are primarily driven by EGFR was incorrect as demonstrated by several clinical trials that attempted inhibition of the EGFR pathway by various means but failed miserably (Chan et al, 2011; Crosby et al, 2013; Lordick et al, 2013; Waddell et al, 2013). We have shown that Yap1 upregulates EGFR at the transcription level and therefore, inhibition of Yap1 lowers the expression of EGFR and reduces cell survival (Song et al, 2015). However, Yap1 inhibitors have not yet been tried against OC and not available in the oncology space.

Our quest has been to identify predictive biomarkers to individualise therapy in patients with OC. Our preclinical data suggest that CSCs seem to play a major role in mediating resistance to therapy in OC. Like ALDH-1 (Ajani et al, 2014), Gli-1 (in the Hh pathway) is related to CSC maintenance. The preclinical data presented in this report suggest that when sensitive cells are made resistant to cytotoxic drug or radiation, the $\mathrm{Hh}$ pathway (particularly, Gli-1) is upregulated. Using modern CRISPR/Cas9 technology and prior established clonogenic assay, we document in the preclinical setting that Gli-1 activates resistance to therapy (chemotherapy as well as radiation). The clinical data are compelling. Nuclear Gli-1 LIs highly correlated with response to chemoradiation. Of great interest here is the tight correlation with pathCR and data are validated in a large independent cohort. We acknowledge that considerably more work is needed before predictive biomarkers can be clinically implemented. However, we believe these compelling results represent early steps in the development of personalised medicine. Identification of extreme resistance affords another opportunity. Here one could conceivably forego chemoradiation but more importantly, discover novel therapeutic targets to overcome resistance. In this vein we have 
A

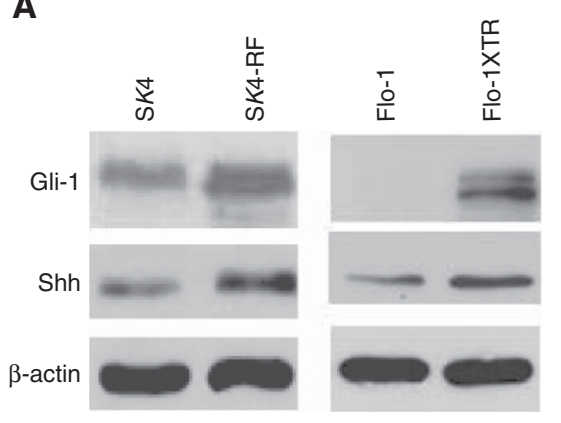

B
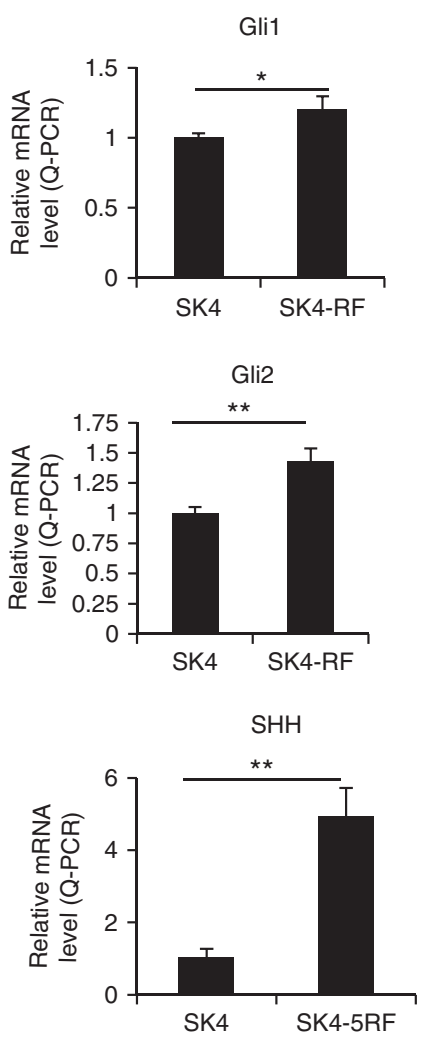

D

E
C
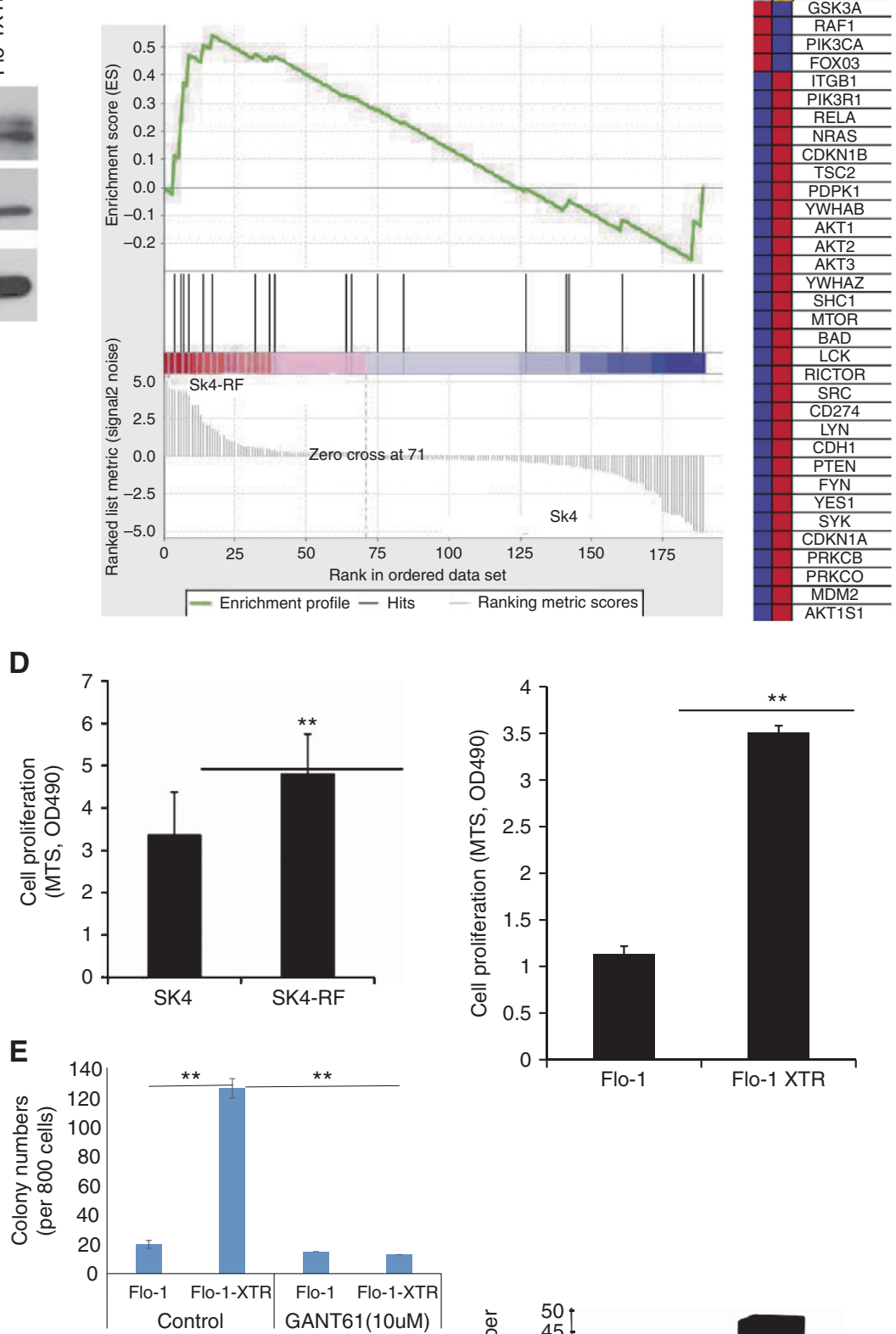

$\mathbf{F}$

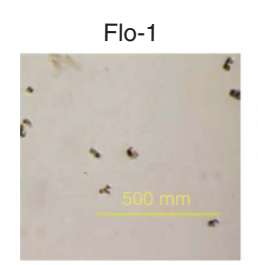

Flo-1XTR

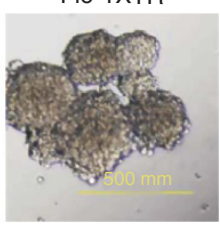

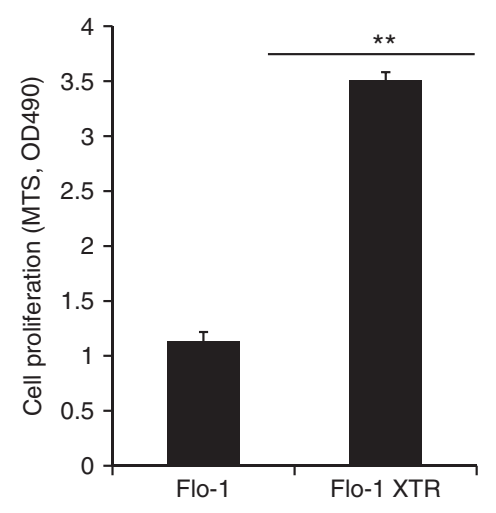

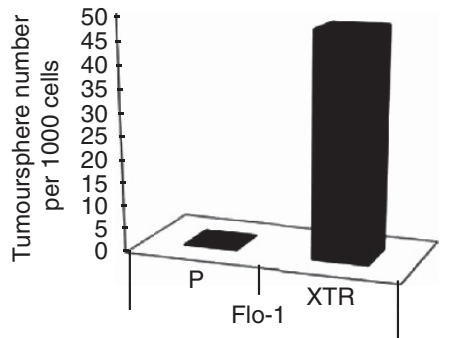

Figure 3. Expression of Hh signalling components is associated with chemoradiation resistance in OC cells. (A) Protein levels of Gli-1 and Shh were determined by immunoblotting in SK-4, Flo-1 EAC cells and their resistant cells SK4-RF and Flo-1-XTR; (B) mRNA level of Hh componentsGli-1, Gli-2 and Shh was determined by quantitative real-time PCR. (C) Gene set enriched analysis of RPPA proteomic data on Sk4 cells and their resistant cells SK4-RF on cell survival signalling and many genes control oncogenic signalling are enriched in chemoresistant OC cells (SK4-RF). (D) Cell proliferation of SK4 cells and their resistant cells SK4-RF and Flo-1 and its radiation resistant cells Flo-1XTR was measured using MTS assay. (E) Colony numbers of Flo-1 and Flo-1XTR cells treated with GANT61 or 100\% ethanol as control, $\star \star P<0.01$. (F) Representative images of tumour spheres (left) and quantification of tumour sphere number (right) are shown in Flo-1 and Flo-1XTR cells. ${ }^{*} P<0.05,{ }^{* *} P<0.01$.

recently discovered that anti-apoptotic agent ABT263 can overcome radiation/chemo resistance by targeting not only BCL-2 protein but also CSCs (Chen et al, 2015).
On the basis of our discoveries (Sims-Mourtada et al, 2006, 2007; Chen et al, 2007) and those of others regarding Gli-1's association with resistance (Zahreddine et al, 2014), we have 
recently initiated a trial with $\mathrm{Hh}$ inhibitor with standard preoperative chemoradiation in patients whose OC's have $\geqslant 5 \%$ LI of nuclear Gli-1 (NCT02530437). In addition, we acknowledge the complexity of cancer biology conferred by ability to reprogram and cross-talk with other pathways to emerge with aggressive phenotype. We believe, Gli-1 alone will not be able to define such complexity in each patient's tumour. Therefore, more work is needed to develop signature or signatures that might perform consistently when clinically implemented.

In conclusion, nuclear Gli-1 LIs correlated well with pathCR in TDS and TVS. We acknowledge that considerably more research would be needed before clinical implementation.

\section{ACKNOWLEDGEMENTS}

Generous grants from the Caporella, Dallas, Sultan, Park, Smith, Frazier, Oaks, Vanstekelenberg, Planjery, and Cantu Families. From the Schecter Private Foundation, Rivercreek Foundation, Kevin Fund, Myer Fund, Dio Fund, Milrod Fund, and Multidisciplinary Grants from the University of Texas M. D. Anderson Cancer Center, Houston, USA. Supported in part by the National Cancer Institute and Department of Defense awards CA138671, CA172741, CA129926, CA150334 (JAA) and P30CA016672. We want to thank Dr Julie G Izzo, Dr Ritsuko Komaki and the Biostatistics Resource Group for their support.

\section{CONFLICT OF INTEREST}

The authors declare no conflict of interest.

\section{REFERENCES}

American Cancer Society (2015) Cancer Facts \& Figures.

Ajani JA, Correa AM, Hofstetter WL, Rice DC, Blum MA, Suzuki A, Taketa T, Welsh J, Lin SH, Lee JH, Bhutani MS, Ross WA, Maru DM,

Macapinlac HA, Erasmus J, Komaki R, Mehran RJ, Vaporciyan AA, Swisher SG (2012) Clinical parameters model for predicting pathologic complete response following preoperative chemoradiation in patients with esophageal cancer. Ann Oncol 23(10): 2638-2642.

Ajani JA, D'Amico TA, Almhanna K, Bentrem DJ, Besh S, Chao J, Das P, Denlinger C, Fanta P, Fuchs CS, Gerdes H, Glasgow RE, Hayman JA, Hochwald S, Hofstetter WL, Ilson DH, Jaroszewski D, Jasperson K, Keswani RN, Kleinberg LR, Korn WM, Leong S, Lockhart AC, Mulcahy MF, Orringer MB, Posey JA, Poultsides GA, Sasson AR, Scott WJ, Strong VE, Varghese Jr TK, Washington MK, Willett CG, Wright CD, Zelman D, McMillian N, Sundar H (2015a) Esophageal and esophagogastric junction cancers, version 1.2015. J Natl Compr Cancer Netw 13(2): 194-227.

Ajani JA, Song S, Hochster HS, Steinberg IB (2015b) Cancer stem cells: the promise and the potential. Semin Oncol 42(Suppl 1): S3-17.

Ajani JA, Wang X, Song S, Suzuki A, Taketa T, Sudo K, Wadhwa R, Hofstetter WL, Komaki R, Maru DM, Lee JH, Bhutani MS, Weston B, Baladandayuthapani V, Yao Y, Honjo S, Scott AW, Skinner HD, Johnson RL, Berry D (2014) ALDH-1 expression levels predict response or resistance to preoperative chemoradiation in resectable esophageal cancer patients. Mol Oncol 8(1): 142-149.

Berger AC, Farma J, Scott WJ, Freedman G, Weiner L, Cheng JD, Wang H, Goldberg M (2005) Complete response to neoadjuvant chemoradiotherapy in esophageal carcinoma is associated with significantly improved survival. J Clin Oncol 23(19): 4330-4337.

Cancer Genome Atlas Research N, Analysis Working Group: Asan U, Agency BCC, Brigham, Women's H, Broad I, Brown U, Case Western Reserve U, Dana-Farber Cancer I, Duke U, Greater Poland Cancer C, Harvard Medical S, Institute for Systems B, Leuven KU, Mayo C, Memorial Sloan Kettering Cancer C, National Cancer I, Nationwide Children's H, Stanford U, University of A, University of M, University of North C, University of P, University of R, University of Southern C,
University of Texas MDACC, University of W, Van Andel Research I, Vanderbilt U, Washington U, Genome Sequencing Center: Broad I, Washington University in St L, Genome Characterization Centers BCCA, Broad I, Harvard Medical S, Sidney Kimmel Comprehensive Cancer Center at Johns Hopkins U, University of North C, University of Southern California Epigenome C, University of Texas MDACC, Van Andel Research I, Genome Data Analysis Centers: Broad I, Brown U, Harvard Medical S, Institute for Systems B, Memorial Sloan Kettering Cancer C, University of California Santa C, University of Texas MDACC,

Biospecimen Core Resource: International Genomics C, Research Institute at Nationwide Children's H, Tissue Source Sites: Analytic Biologic S, Asan Medical C, Asterand B, Barretos Cancer H, BioreclamationIvt, Botkin Municipal C, Chonnam National University Medical S, Christiana Care Health S, Cureline, Duke U, Emory U, Erasmus U, Indiana University School of M, Institute of Oncology of M, International Genomics C, Invidumed, Israelitisches Krankenhaus H, Keimyung University School of M, Memorial Sloan Kettering Cancer C, National Cancer Center G, Ontario Tumour B, Peter MacCallum Cancer C, Pusan National University Medical S, Ribeirao Preto Medical S, St Joseph's H, Medical C, St Petersburg Academic U, Tayside Tissue B, University of D, University of Kansas Medical C, University of M, University of North Carolina at Chapel H, University of Pittsburgh School of M, University of Texas MDACC, Disease Working Group: Duke U, Memorial Sloan Kettering Cancer C, National Cancer I, University of Texas MDACC, Yonsei University College of M, Data Coordination Center CI, Project Team: National Institutes of Health (2017) Integrated genomic characterization of oesophageal carcinoma. Nature 541(7636): 169-175.

Chan JA, Blaszkowsky LS, Enzinger PC, Ryan DP, Abrams TA, Zhu AX, Temel JS, Schrag D, Bhargava P, Meyerhardt JA, Wolpin BM, Fidias P, Zheng H, Florio S, Regan E, Fuchs CS (2011) A multicenter phase II trial of single-agent cetuximab in advanced esophageal and gastric adenocarcinoma. Ann Oncol 22(6): 1367-1373.

Cheedella NK, Suzuki A, Xiao L, Hofstetter WL, Maru DM, Taketa T, Sudo K, Blum MA, Lin SH, Welch J, Lee JH, Bhutani MS, Rice DC,

Vaporciyan AA, Swisher SG, Ajani JA (2013) Association between clinical complete response and pathological complete response after preoperative chemoradiation in patients with gastroesophageal cancer: analysis in a large cohort. Ann Oncol 24(5): 1262-1266.

Chen Q, Song S, Wei S, Liu B, Honjo S, Scott A, Jin J, Ma L, Zhu H, Skinner HD, Johnson RL, Ajani JA (2015) ABT-263 induces apoptosis and synergizes with chemotherapy by targeting stemness pathways in esophageal cancer. Oncotarget 6(28): 25883-25896.

Chen YJ, Sims-Mourtada J, Izzo J, Chao KS (2007) Targeting the hedgehog pathway to mitigate treatment resistance. Cell Cycle 6(15): 1826-1830.

Chirieac LR, Swisher SG, Ajani JA, Komaki RR, Correa AM, Morris JS, Roth JA, Rashid A, Hamilton SR, Wu TT (2005) Posttherapy pathologic stage predicts survival in patients with esophageal carcinoma receiving preoperative chemoradiation. Cancer 103(7): 1347-1355.

Coni S, Infante P, Gulino A (2013) Control of stem cells and cancer stem cells by Hedgehog signaling: pharmacologic clues from pathway dissection. Biochem Pharmacol 85(5): 623-628.

Cooper JS, Guo MD, Herskovic A, Macdonald JS, Martenson Jr JA, Al-Sarraf M, Byhardt R, Russell AH, Beitler JJ, Spencer S, Asbell SO, Graham MV, Leichman LL (1999) Chemoradiotherapy of locally advanced esophageal cancer: long-term follow-up of a prospective randomized trial (RTOG 85-01). Radiation Therapy Oncology Group. JAMA 281(17): 1623-1627.

Crosby T, Hurt CN, Falk S, Gollins S, Mukherjee S, Staffurth J, Ray R, Bashir N, Bridgewater JA, Geh JI, Cunningham D, Blazeby J, Roy R, Maughan T, Griffiths G (2013) Chemoradiotherapy with or without cetuximab in patients with oesophageal cancer (SCOPE1): a multicentre, phase 2/3 randomised trial. Lancet Oncol 14(7): 627-637.

Cui D, Xu Q, Wang K, Che X (2010) Gli1 is a potential target for alleviating multidrug resistance of gliomas. J Neurol Sci 288(1-2): 156-166.

Donahue JM, Nichols FC, Li Z, Schomas DA, Allen MS, Cassivi SD, Jatoi A, Miller RC, Wigle DA, Shen KR, Deschamps C (2009) Complete pathologic response after neoadjuvant chemoradiotherapy for esophageal cancer is associated with enhanced survival. Ann Thorac Surg 87(2): 392-398 discussion 398-9.

Dontu G, Abdallah WM, Foley JM, Jackson KW, Clarke MF, Kawamura MJ, Wicha MS (2003) In vitro propagation and transcriptional profiling of human mammary stem/progenitor cells. Genes Dev 17(10): 1253-1270. 
He S, Wang F, Yang L, Guo C, Wan R, Ke A, Xu L, Hu G, Xu X, Shen J, Wang X (2011) Expression of DNMT1 and DNMT3a are regulated by GLI1 in human pancreatic cancer. PLoS One 6(11): e27684.

Hennessy BT, Lu Y, Gonzalez-Angulo AM, Carey MS, Myhre S, Ju Z, Davies MA, Liu W, Coombes K, Meric-Bernstam F, Bedrosian I, McGahren M, Agarwal R, Zhang F, Overgaard J, Alsner J, Neve RM, Kuo WL, Gray JW, Borresen-Dale AL, Mills GB (2010) A Technical Assessment of the Utility of Reverse Phase Protein Arrays for the Study of the Functional Proteome in Non-microdissected Human Breast Cancers. ClinProteom 6(4): 129-151.

Kaplan EL, Meier P (1958) Nonparametric Estimation from Incomplete Observations. J Am Stat Assoc 53(282): 457-481.

Karhadkar SS, Bova GS, Abdallah N, Dhara S, Gardner D, Maitra A, Isaacs JT, Berman DM, Beachy PA (2004) Hedgehog signalling in prostate regeneration, neoplasia and metastasis. Nature 431(7009): 707-712.

Lordick F, Kang YK, Chung HC, Salman P, Oh SC, Bodoky G, Kurteva G, Volovat C, Moiseyenko VM, Gorbunova V, Park JO, Sawaki A, Celik I, Gotte H, Melezinkova H, Moehler M, Arbeitsgemeinschaft Internistische O, Investigators E (2013) Capecitabine and cisplatin with or without cetuximab for patients with previously untreated advanced gastric cancer (EXPAND): a randomised, open-label phase 3 trial. Lancet Oncol 14(6): 490-499.

Mantel N (1996) Evaluation of survival data and two new rank order statistics arising in ints consideration. Cancer Chemother Rep 60: 163-170.

Nagai S, Nakamura M, Yanai K, Wada J, Akiyoshi T, Nakashima H, Ohuchida K, Sato N, Tanaka M, Katano M (2008) Glil contributes to the invasiveness of pancreatic cancer through matrix metalloproteinase- 9 activation. Cancer Sci 99(7): 1377-1384.

Onishi H, Katano M (2011) Hedgehog signaling pathway as a therapeutic target in various types of cancer. Cancer Sci 102(10): 1756-1760.

Park KS, Martelotto LG, Peifer M, Sos ML, Karnezis AN, Mahjoub MR, Bernard K, Conklin JF, Szczepny A, Yuan J, Guo R, Ospina B, Falzon J, Bennett S, Brown TJ, Markovic A, Devereux WL, Ocasio CA, Chen JK, Stearns T, Thomas RK, Dorsch M, Buonamici S, Watkins DN, Peacock CD, Sage J (2011) A crucial requirement for Hedgehog signaling in small cell lung cancer. Nat Med 17(11): 1504-1508.

Pasca di Magliano M, Hebrok M (2003) Hedgehog signalling in cancer formation and maintenance. Nat Rev 3(12): 903-911.

Po A, Ferretti E, Miele E, De Smaele E, Paganelli A, Canettieri G, Coni S, Di Marcotullio L, Biffoni M, Massimi L, Di Rocco C, Screpanti I, Gulino A (2010) Hedgehog controls neural stem cells through p53-independent regulation of Nanog. EMBO J 29(15): 2646-2658.

Raju U, Ariga H, Koto M, Lu X, Pickett J, Valdecanas D, Mason KA, Milas L (2006) Improvement of esophageal adenocarcinoma cell and xenograft responses to radiation by targeting cyclin-dependent kinases. Radiother Oncol 80(2): 185-191.

Rizk NP, Venkatraman E, Bains MS, Park B, Flores R, Tang L, Ilson DH, Minsky BD, Rusch VW (2007) American Joint Committee on Cancer staging system does not accurately predict survival in patients receiving multimodality therapy for esophageal adenocarcinoma. J Clin Oncol 25(5): 507-512.

Rohatgi P, Swisher SG, Correa AM, Wu TT, Liao Z, Komaki R, Walsh GL, Vaporciyan AA, Rice DC, Roth JA, Ajani JA (2005a) Characterization of pathologic complete response after preoperative chemoradiotherapy in carcinoma of the esophagus and outcome after pathologic complete response. Cancer 104(11): 2365-2372.

Rohatgi PR, Swisher SG, Correa AM, Wu TT, Liao Z, Komaki R, Walsh G, Vaporciyan A, Lynch PM, Rice DC, Roth JA, Ajani JA (2005b) Failure patterns correlate with the proportion of residual carcinoma after preoperative chemoradiotherapy for carcinoma of the esophagus. Cancer 104(7): 1349-1355.

Rudin CM, Hann CL, Laterra J, Yauch RL, Callahan CA, Fu L, Holcomb T, Stinson J, Gould SE, Coleman B, Lorusso PM, Von Hoff DD, de Sauvage FJ, Low JA (2009) Treatment of Medulloblastoma with Hedgehog Pathway Inhibitor GDC-0449. N Engl J Med 361(12): 1173-1178.

Sims-Mourtada J, Izzo JG, Ajani J, Chao KS (2007) Sonic Hedgehog promotes multiple drug resistance by regulation of drug transport. Oncogene 26(38): 5674-5679.

Sims-Mourtada J, Izzo JG, Apisarnthanarax S, Wu TT, Malhotra U, Luthra R, Liao Z, Komaki R, van der Kogel A, Ajani J, Chao KS (2006) Hedgehog: an attribute to tumor regrowth after chemoradiotherapy and a target to improve radiation response. Clin Cancer Res 12(21): 6565-6572.

Soldes OS, Kuick RD, Thompson Ii IA, Hughes SJ, Orringer MB, Iannettoni MD, Hanash SM, Beer DG (1999) Differential expression of Hsp27 in normal oesophagus, Barrett/'s metaplasia and oesophageal adenocarcinomas. Br J Cancer 79(3-4): 595-603.

Song S, Ajani JA, Honjo S, Maru DM, Chen Q, Scott AW, Heallen TR, Xiao L, Hofstetter WL, Weston B, Lee JH, Wadhwa R, Sudo K, Stroehlein JR, Martin JF, Hung MC, Johnson RL (2014) Hippo coactivator YAP1 upregulates SOX9 and endows esophageal cancer cells with stem-like properties. Cancer Res 74(15): 4170-4182.

Song S, Honjo S, Jin J, Chang SS, Scott AW, Chen Q, Kalhor N, Correa AM, Hofstetter WL, Albarracin CT, Wu TT, Johnson RL, Hung MC, Ajani JA (2015) The hippo coactivator YAP1 mediates EGFR overexpression and confers chemoresistance in esophageal cancer. Clin Cancer Res 21(11): 2580-2590.

Souzaki M, Kubo M, Kai M, Kameda C, Tanaka H, Taguchi T, Tanaka M, Onishi H, Katano M (2011) Hedgehog signaling pathway mediates the progression of non-invasive breast cancer to invasive breast cancer. Cancer Sci 102(2): 373-381.

van Hagen P, Hulshof MCCM, van Lanschot JJB, Steyerberg EW, Henegouwen MIvB, Wijnhoven BPL, Richel DJ, Nieuwenhuijzen GAP, Hospers GAP, Bonenkamp JJ, Cuesta MA, Blaisse RJB, Busch ORC, ten Kate FJW, Creemers GJ, Punt CJA, Plukker JTM, Verheul HMW, Bilgen EJS, van Dekken H (2012) Preoperative chemoradiotherapy for esophageal or junctional cancer. N Engl J Med 366(22): 2074-2084.

Von Hoff DD, Lorusso PM, Rudin CM, Reddy JC, Yauch RL, Tibes R, Weiss GJ, Borad MJ, Hann CL, Brahmer JR, Mackey HM, Lum BL, Darbonne WC, Marsters Jr JC, de Sauvage FJ, Low JA (2009) Inhibition of the hedgehog pathway in advanced basal-cell carcinoma. N Engl J Med 361(12): 1164-1172.

Waddell T, Chau I, Cunningham D, Gonzalez D, Okines AF, Okines C, Wotherspoon A, Saffery C, Middleton G, Wadsley J, Ferry D, Mansoor W, Crosby T, Coxon F, Smith D, Waters J, Iveson T, Falk S, Slater S, Peckitt C, Barbachano Y (2013) Epirubicin, oxaliplatin, and capecitabine with or without panitumumab for patients with previously untreated advanced oesophagogastric cancer (REAL3): a randomised, open-label phase 3 trial. Lancet Oncol 14(6): 481-489.

Wang KL, Wu TT, Choi IS, Wang H, Resetkova E, Correa AM, Hofstetter WL, Swisher SG, Ajani JA, Rashid A, Albarracin CT (2007) Expression of epidermal growth factor receptor in esophageal and esophagogastric junction adenocarcinomas: association with poor outcome. Cancer 109(4): 658-667.

Wang Y, Ding $\backslash$ Q, Yen CJ, Xia W, Izzo JG, Lang JY, Li CW, Hsu JL, Miller SA, Wang X, Lee DF, Hsu JM, Huo L, Labaff AM, Liu D, Huang TH, Lai CC, Tsai FJ, Chang WC, Chen CH, Wu TT, Buttar NS, Wang KK, Wu Y, Wang H, Ajani J, Hung MC (2012) The crosstalk of mTOR/S6K1 and Hedgehog pathways. Cancer Cell 21(3): 374-387.

Wu TT, Chirieac LR, Abraham SC, Krasinskas AM, Wang H, Rashid A, Correa AM, Hofstetter WL, Ajani JA, Swisher SG (2007) Excellent interobserver agreement on grading the extent of residual carcinoma after preoperative chemoradiation in esophageal and esophagogastric junction carcinoma: a reliable predictor for patient outcome. Am J Surg Pathol 31(1): 58-64.

Yoshikawa R, Nakano Y, Tao L, Koishi K, Matsumoto T, Sasako M, Tsujimura T, Hashimoto-Tamaoki T, Fujiwara Y (2008) Hedgehog signal activation in oesophageal cancer patients undergoing neoadjuvant chemoradiotherapy. Br J Cancer 98(10): 1670-1674.

Zahreddine HA, Culjkovic-Kraljacic B, Assouline S, Gendron P, Romeo AA, Morris SJ, Cormack G, Jaquith JB, Cerchietti L, Cocolakis E, Amri A, Bergeron J, Leber B, Becker MW, Pei S, Jordan CT, Miller WH, Borden KLB (2014) The sonic hedgehog factor GLI1 imparts drug resistance through inducible glucuronidation. Nature 511(7507): 90-93.

This work is published under the standard license to publish agreement. After 12 months the work will become freely available and the license terms will switch to a Creative Commons AttributionNonCommercial-Share Alike 4.0 Unported License. 